\title{
FUNÇÃO SOCIAL DA PROPRIEDADE RURAL: UMA REGRA CONSTITUCIONAL
}

\author{
RURAL PROPERTY'S SOCIAL FUNCTION: \\ A CONSTITUTIONAL RULE
}

\author{
Pedro Felippe Tayer Neto* \\ João da Cruz Gonçalves Neto**
}

\begin{abstract}
RESUMO: Este artigo se divide em duas etapas. Na primeira, buscar-se-á averiguar quais são os critérios utilizados na Teoria do Direito para diferenciar as espécies normativas, geralmente separadas entre princípios e regras. Serão utilizadas duas correntes teóricas: a clássica, formulada entre as décadas de 1970 e 1980 por Ronald Dworkin e Robert Alexy, e a concepção encabeçada por um de seus críticos, Humberto Ávila. Tendo em vista as teorias, será demonstrado, na segunda etapa, como a função social da propriedade rural, norma obtida por meio da interpretação dos arts. $5^{\circ}$, XXII, e art. 186, ambos da Constituição, possui natureza jurídica de regra e não de princípio, como geralmente é alegado.
\end{abstract}

PALAVRAS CHAVE: Direito Agrário. Função social. Princípios e regras.

ABSTRACT: This article is divided in two stages. At first, it will seek to ascertain which criteria is used in legal theory to differentiate the regulation's species, usually separated between principles and rules. Two theoretical perspectives will be used: the classic, created between the seventies and eighties by Ronald Dworkin and Robert Alexy, and the conception headed by one of his critics, Humberto Ávila. Considering the theories, it will be established, in the second stage, how the rural property's social function norm, obtained by interpretation from article $5^{\circ}$, XXII, and article 186, both from Constitution, has the legal nature of rule and not principle, as it is usually claimed.

KEYWORDS: Agrarian Law. Social function. Principles and rules.

* Mestrando em Direito Agrário pela Universidade Federal de Goiás (UFG). Advogado. E-mail: pedrotayer@gmail.com.

**Doutor em Filosofia pela Pontifícia Universidade Católica do Rio Grande do Sul (PUCRS). Professor do Programa de Pós-Graduação da Universidade Federal de Goiás (UFG). E-mail: dellacroce@ dellacroce.pro.br. 
O debate a respeito da diferença qualitativa entre as espécies normativas, em geral identificadas como princípios ou regras, não é novidade para o ramo do Direito. $\mathrm{O}$ tema, entretanto, ainda desperta grande interesse, mesmo três décadas depois de "O modelo de regras I e II", de Ronald Dworkin, e "Teoria dos Direitos Fundamentais", de Robert Alexy, responsáveis pela popularização das discussões.

No Brasil, as discussões ganharam força em momento relativamente recente, já sob a égide da atual Constituição. Por ser uma Carta com forte carga principiológica, que em muito extrapolou o papel clássico atribuído às Constituições ocidentais, de regulamentar a organização político-administrativa dos Estados, e, por sua própria natureza, hierarquicamente superior a todas as demais normas, é natural que a natureza jurídica das normas extraídas de seus dispositivos se tornassem alvo de um intenso debate teórico, uma vez que não se pode falar em aplicabilidade de normas constitucionais antes mesmo de entender qual é a natureza dessas mesmas normas. Regras são aplicadas de maneira distinta de princípios, e existem, ainda, aqueles que defendem a insuficiência desse binômio, pregando a existência de uma terceira divisão para a categoria.

Ocorre, entretanto, que nem todas as normas extraídas da Constituição da República têm sido tratadas com o apreço técnico que merecem. O objetivo deste artigo é explorar uma dessas normas especificamente, a "função social da propriedade rural", que é extraída da interpretação do art. 5\%, inciso XXII ("é garantido o direito de propriedade"), conjuntamente com o art. 186 e incisos, da Constituição da República vigente:

Art. 186 - A função social é cumprida quando a propriedade rural atende, simultaneamente, segundo critérios e graus de exigência estabelecidos em lei, aos seguintes requisitos:

I - aproveitamento racional e adequado;

II - utilização adequada dos recursos naturais disponíveis e preservação do meio ambiente;

III - observância das disposições que regulam as relações de trabalho;

IV - exploração que favoreça o bem-estar dos proprietários e dos trabalhadores. (BRASIL, 1988).

Cumpre, primeiramente, fazer uma importante ressalva. Como leciona o José Afonso da Silva (1994, p. 266), nossa Carta Maior adotou a tese da propriedade como um instituto jurídico complexo. Não existe apenas uma forma de propriedade, mas várias. Desta forma, a norma jurídica que aqui se busca explorar é a função social da propriedade rural. Não se pretende explorar toda forma de função social, assim como não se pretende explorar toda forma de propriedade. 
Sendo assim, como será demonstrado, baseando-se no art. $5^{\circ}$, XXII, e no art. 186, da Constituição, os estudiosos nacionais sedimentaram a função social da propriedade rural na categoria normativa de princípio, e assim o tema vem sendo tratado, com pouca ou nenhuma discussão. O objetivo deste artigo é justamente demonstrar como a função social da propriedade rural possui, na realidade, natureza jurídica de regra.

Finalmente, deve-se ressaltar que o correto enquadramento técnico do dispositivo possui enorme relevância. A rigor do caput do art. 184, da Constituição:

Compete à União desapropriar por interesse social, para fins de reforma agrária, o imóvel rural que não esteja cumprindo sua função social, mediante prévia e justa indenização em títulos da dívida agrária, com cláusula de preservação do valor real, resgatáveis no prazo de até vinte anos, a partir do segundo ano de sua emissão, e cuja utilização será definida em lei. (BRASIL, 1988).

O principal instrumento utilizado pela União para a promoção da reforma agrária no Brasil, um país cuja economia possui laços estreitos com a atividade agrária, é a desapropriação por interesse social, que pressupõe o descumprimento, por parte de uma propriedade, de uma norma constitucional, justamente a regra da função social da propriedade. Uma incorreta aplicação do dispositivo constitucional afetaria toda a política de reforma agrária empreendida pelo Estado, o que traria inegável prejuízo social.

\section{NORMAS, PRINCÍPIOS E REGRAS}

Ronald Dworkin é geralmente apontado como o precursor das discussões a respeito da diferenciação das normas jurídicas em princípios e regras. Em sua obra "Levando os Direitos a Sério" (Taking Rights Seriously, no original de 1977), o autor formula a distinção das normas em princípios e regras como forma de demonstrar a insuficiência dos postulados positivistas, garantindo especial atenção à obra de seu antecessor em Oxford, o jurista H. L. A. Hart. Nas palavras do próprio Dworkin, o modelo de sistema jurídico defendido pelos postulados positivistas pode ser resumido em três pilares:

(a) O direito de uma comunidade é um conjunto de regras especiais utilizado direta ou indiretamente pela comunidade com o propósito de determinar qual comportamento será punido ou coagido pelo poder público. Essas regras podem ser identificadas e distinguidas com auxílio de critérios específicos, de testes que não têm a ver com seu conteúdo, mas com seu pedigree ou maneira pela qual foram adotadas ou formuladas. $[\cdots]$ 
(b) O conjunto dessas regras jurídicas é coextensivo com "o direito", de modo que se o caso de alguma pessoa não estiver claramente coberto por uma regra dessas (porque não existe nenhuma que pareça apropriada ou porque as que parecem apropriadas são vagas ou por alguma outra razão), então esse caso não pode ser decidido mediante "a aplicação do direito". Ele deve ser decidido por alguma autoridade pública, como um juiz, "exercendo seu discernimento pessoal", o que significa ir além do direito na busca por algum outro tipo de padrão que o oriente na confecção de nova regra jurídica ou na complementação de uma regra já existente.

(c) Dizer quer alguém tem uma "obrigação jurídica" é dizer que seu caso se enquadra em uma regra jurídica válida que exige que ele faça ou se abstenha de fazer alguma coisa. (Dizer que ele tem um direito jurídico, ou um poder jurídico de algum tipo, ou um privilégio ou imunidades jurídicos é asseverar de maneira taquigráfica que outras pessoas têm obrigações jurídicas reais ou hipotéticas de agir ou não agir de determinadas maneiras que o afetem.) $\mathrm{Na}$ ausência de tal regra jurídica válida não existe obrigação jurídica; segue-se que quando o juiz decide uma matéria controversa exercendo sua discrição, ele não está fazendo valer um direito jurídico correspondente a essa matéria. (DWORKIN, 2010, p. 27-28).

A constatação da existência dos princípios jurídicos como espécie do gênero norma contrariaria, de uma só vez, os três pilares do positivismo jurídico. Para Dworkin, os casos difíceis (hard cases), aqueles casos nos quais não existe uma solução pronta, que possa ser obtida pela simples aplicação de uma regra de direito já anteriormente estabelecida pela instituição adequada (DWORKIN, 2010, p. 127), são emblemáticos para demonstrar a insuficiência positivista. Como demonstra o autor, os casos difíceis são solucionados pelo positivismo jurídico por meio da utilização da discricionariedade do julgador, efetivamente criando uma nova regra jurídica, que ainda não havia sido concebida, e aplicando-a retroativamente aos fatos sub judice, de forma a determinar o direito. Esse modo de solucionar os conflitos seria inadequado.

Para o autor, entretanto, o fato de não existirem regras específicas que apontem para a solução do conflito não indica a impossibilidade de se obter uma solução. "O juiz continua tendo o dever, mesmo nos casos difíceis, de descobrir quais são os direitos das partes, e não de inventar novos direitos retroativamente" (DWORKIN, 2010, p. 127). A solução de casos difíceis é, portanto, uma questão de princípios.

Os princípios jurídicos exercem um papel fundamental na crítica formulada por Dworkin ao positivismo e, por isso, sua diferenciação das regras mereceu especial atenção. Nas palavras do autor: 
A diferença entre princípios jurídicos e regras jurídicas é de natureza lógica. Os dois conjuntos de padrões apontam para decisões particulares acerca da obrigação jurídica em circunstâncias específicas, mas distinguem-se quanto à natureza da orientação que oferecem. As regras são aplicáveis à maneira do tudo ou nada. Dados os fatos que uma regra estipula, então ou a regra é válida, e neste caso a resposta que ela fornece deve ser aceita, ou não é válida, e neste caso em nada contribui para a decisão. [...]

Mas não é assim que funcionam os princípios apresentados como exemplos nas citações. Mesmo aqueles que mais se assemelham a regras não apresentam consequências jurídicas que se seguem automaticamente quando as condições são dadas. (DWORKIN, 2010, p. 39-40).

A forma de aplicação seria, assim, o principal critério para diferenciar as espécies normativas. Regras são aplicadas na medida de "tudo ou nada", expressão consagrada por Dworkin. São aplicáveis ou não a determinados fatos. Trata-se de um critério de validade. Os princípios, por outro lado, não podem ser aplicados desta forma, uma vez que raramente trazem as consequências de sua aplicação. Essa diferenciação acaba trazendo outra consigo:

Os princípios possuem uma dimensão que as regras não têm - a dimensão do peso ou importância. Quando os princípios se entrecruzam (por exemplo, a política de proteção aos compradores de automóveis se opõe aos princípios de liberdade de contrato), aquele que vai resolver o conflito tem de levar em conta a força relativa de cada um. Esta não pode ser, por certo, uma mensuração exata e o julgamento que determina que um princípio ou uma política particular é mais importante que outra frequentemente será objeto de controvérsia. Não obstante, essa dimensão é uma parte integrante do conceito de princípio, de modo que faz sentido perguntar que peso ele tem ou quão importante ele é.

As regras não têm essa dimensão. Podemos dizer que as regras são funcionalmente importantes ou desimportantes [...]. Nesse sentido, uma regra jurídica pode ser mais importante do que outra porque desempenha um papel maior ou mais importante na regulação do comportamento. Mas não podemos dizer que uma regra é mais importante que outra enquanto parte do mesmo sistema de regras, de tal modo que se duas regras estão em conflito, uma suplanta a outra em virtude de sua importância maior (DWORKIN, 2010, p. 42-43).

Existe, portanto, entre princípios, uma dimensão de peso ou importância. Em um determinado caso concreto, é possível averiguar, dentre diversos princípios que poderiam incidir sobre a questão, a existência daqueles com maior peso ou importância, devendo estes prevalecer sobre os demais. Já as regras não possuem essa dimensão. Não é possível dizer que uma regra deverá prevalecer sobre outra 
por ter maior peso ou ser mais importante. É comum, inclusive, que ordenamentos jurídicos instituam regras próprias para determinar a solução para o conflito entre as diversas regras, em geral baseando-se em aspectos formais. É o caso brasileiro. Dentre diversos exemplos, temos o Decreto 4.657/42, renomeado como "Lei de Introdução às Normas do Direito Brasileiro":

Art. $2^{\circ}-$ Não se destinando à vigência temporária, a lei terá vigor até que outra a modifique ou revogue.

$\S 1^{\circ}$ A lei posterior revoga a anterior quando expressamente o declare, quando seja com ela incompatível ou quando regule inteiramente a matéria de que tratava a lei anterior. $\S 2^{\circ}$ A lei nova, que estabeleça disposições gerais ou especiais a par das já existentes, não revoga nem modifica a lei anterior.

$\S 3^{\circ}$ Salvo disposição em contrário, a lei revogada não se restaura por ter a lei revogadora perdido a vigência. (BRASIL, 1942, p.1).

É necessário lembrar que Ronald Dworkin escreve baseado na tradição jurídica dos Estados Unidos e da Inglaterra, sistemas jurídicos classificados como common law, nos quais frequentemente os princípios jurídicos são extraídos de forma indireta de dispositivos legais. Nos sistemas de influência romano-germânica, como o Brasil, por outro lado, é frequente que os textos normativos que instituem princípios também determinem as consequências para o descumprimento dos mandamentos.

Não se espanta, portanto, a grande receptibilidade que a teoria de Robert Alexy recebeu no Brasil. Escrevendo especificamente sobre a distinção entre princípios e regras em um ordenamento jurídico de tradição romano-germânica, esse autor seguiu a linha proposta por Dworkin, confirmando que a distinção entre as espécies de norma era efetivamente qualitativa, todavia, foi sua definição de princípios que ganhou notoriedade:

O ponto decisivo na distinção entre regras e princípios é que princípios são normas que ordenam que algo seja realizado na maior medida do possível dentro das possibilidades jurídicas e fáticas existentes. Princípios são, por conseguinte, mandamentos de otimização, que são caracterizados por poderem ser satisfeitos em graus variados e pelo fato de que a medida devida de sua satisfação não depende somente das possibilidades fáticas, mas também das possibilidades jurídicas. $\mathrm{O}$ âmbito das possibilidades jurídicas é determinado pelos princípios e regras colidentes.

Já as regras são normas que são sempre ou satisfeitas ou não satisfeitas. Se uma regra vale, então, deve fazer exatamente aquilo que ela exige; nem mais, nem menos. Regras contêm, portanto, determinações no âmbito daquilo que é fática e juridicamente possível. Isso significa que a distinção entre regras e princípios é uma distinção qualitativa, e não uma distinção de grau. Toda norma é ou uma regra ou um princípio. (ALEXY, 2008, p. 90-91). 
A caracterização dos princípios como "mandamentos de otimização", ou seja, como normas que devem ser observadas na maior medida do possível, é, como o narra o próprio Alexy (2008, p. 91), o ponto que separa a sua teoria da formulada por Dworkin. Como aponta Virgílio Afonso da Silva (2003, p. 602), a principal consequência dessa distinção será a solução apresentada pelos autores para os casos de colisão entre princípios. Dworkin defenderá "uma única resposta correta", que deverá ser extraída da análise do ordenamento jurídico como um todo, entendido em sua integridade. Alexy, por outro lado, defenderá que os princípios expressam deveres e direitos prima facie, "que poderão revelar-se menos amplos após o sopesamento com princípios colidentes" (SILVA, 2003, p. 612).

A diferenciação de normas em regras e princípios é a base da crítica ao positivismo jurídico elaborada por Dworkin. Segundo o autor (DWORKIN, 2010, p. 27-28), o positivismo jurídico, apesar de possuir diversas nuances, em geral entendia que o todo ordenamento jurídico complexo possui um teste formal capaz de identificar as normas existentes naquele sistema, e que o direito é coextensivo a essas normas. Quando não existirem normas identificáveis pelo teste formal aptas a indicarem uma solução, o juiz (ou a autoridade pública incumbida de julgar) estará incapacitado de decidir utilizando a aplicação do direito, estando obrigado a empregar seu discernimento pessoal (discricionariedade).

Esse entendimento, continua o autor, acaba gerando uma contradição na noção de obrigação jurídica. Dizer-se que uma pessoa possui uma obrigação jurídica (DWORKIN, 2010, p. 28-29) é afirmar que existe uma norma jurídica válida, anterior, exigindo que se faça ou deixe de fazer alguma coisa, então um julgamento que utilize a discricionariedade estaria exigindo de pelo menos uma das partes a implementação de uma obrigação jurídica inexistente à época dos fatos. Nestes casos, os julgadores estariam criando uma nova norma jurídica (assim como uma nova obrigação jurídica) e aplicando-a retroativamente.

Trata-se, segundo o autor, de um entendimento limitado a respeito da natureza da atividade jurídica, que tem "por finalidade descobrir, e não inventar, os direitos das partes interessadas [...]." (DWORKIN, 2010, p. 430). A controvertida tese do autor, em apertada síntese, defende que mesmo nos casos difíceis, ou seja, naqueles em que não existem regras jurídicas claras que possam apontar alguma direção, o julgador deverá decidir de acordo com princípios jurídicos em vigor e anteriores ao fato, que deverão ser utilizados para solucionar o caso por meio dos padrões do Direito.

As obrigações jurídicas não são derivadas exclusivamente de regras jurídicas, mas também de princípios, de tal sorte que mesmo quando não existir 
uma regra identificada específica para tutelar uma obrigação, não significará que não existe resposta jurídica para o caso. As decisões baseadas em princípio são tão jurídicas como aquelas baseadas em regras.

Se o papel do intérprete é descobrir a obrigação jurídica anterior à decisão das partes, e não criar uma nova obrigação e aplicá-la retroativamente, não caberá ao intérprete escolher (discricionariamente) entre várias "decisões possíveis", mas sim descobrir a "única resposta correta" para aquele caso.

Para Alexy (2008, p. 97-99), só é possível entender adequadamente a aplicação dos princípios, especialmente nos casos de colisão com outros princípios, no momento de sua concretização, ou seja, no momento de sua aplicação. Não há solução pronta anterior ao fato, esperando para ser descoberta. Na obra de Alexy, a colisão deve ser resolvida por meio da ponderação entre os princípios conflitantes, criando, para cada caso concreto, uma regra específica de prevalência:

Essa lei, que será chamada de "lei de colisão", é um dos fundamentos da teoria dos princípios aqui defendida. Ela reflete a natureza dos princípios como mandamentos de otimização: em primeiro lugar, a inexistência de relação absoluta de precedência e, em segundo lugar, sua referência a ações e situações que não são quantificáveis. Ao mesmo tempo, constituem eles a base para a resposta a objeções que se apoiam na proximidade da teoria dos princípios com a teoria dos valores. (ALEXY, 2008, p. 99).

Desta forma, pode-se afirmar que a classificação das espécies normativas efetuadas por Ronald Dworkin e Robert Alexy são muito parecidas entre si, todavia, quando se adentra às consequências da distinção efetuada, há efetiva distinção.

Apesar do amplo reconhecimento da comunidade jurídica às teorias, concomitantemente, diversos outros critérios continuaram sendo aplicados, ainda que de forma secundária. Apesar de alguns desses critérios carecerem de maior consistência, especialmente quando analisados individualmente, não se pode negar a sua importância para, na expressão de Barcellos (2002, p. 46), a formação de um "mapa mental" auxiliar para a distinção. Canotilho, por exemplo, elencou estes critérios em cinco eixos:

a) O grau de abstracção: os princípios são normas com um grau de abstracção relativamente elevado; de modo diverso, as regras possuem uma abstração relativamente reduzida.

b) Grau de determinabilidade na aplicação do caso concreto: os princípios, por serem vagos e indeterminados, carecem de mediações concretizadoras (do legislador? Do juiz?), enquanto as regras são susceptíveis de aplicação directa.

c) Carácter de fundamentalidadeno sistema das fontes de direito: os princípios são normas de natureza ou com um papel fundamental no ordenamento jurídico devido à sua posição hierárquica no sistema das fontes [...] 
d) "Proximidade" da ideia de direito: os princípios são standards juridicamente vinculantes radicados nas exigências de justiça (Dworkin) ou na ideia de direito (Larenz); as regras podem ser normas vinculativas com um conteúdo meramente funcional.

e) Natureza normogenética: os princípios são fundamento de regras, isto é, são normas que estão na base ou constituem a ratio de regras jurídicas, desempenhando, por isso, uma função normogenética fundamentalmente. (CANOTILHO, 1991, p. 172-173).

Barcellos (2002, p. 46-57), por sua vez, discrimina sete critérios de distinção: conteúdo, origem e validade, compromisso histórico, função no ordenamento, estrutura linguística, esforço interpretativo exigido e aplicação. Dois destes critérios merecem maior destaque. Tratam-se dos critérios do compromisso histórico e da função no ordenamento:

c) Compromisso histórico. Os princípios são para muitos (ainda que não todos), em maior ou menor medida, universais, absolutos, objetivos e permanentes, ao passo que as regras caracterizam-se de forma bastante evidente pela contingência e relatividade de seus conteúdos, dependendo do tempo e lugar.

d) Função no ordenamento. Os princípios têm uma função explicadora e justificadora em relação às regras. Ao modo dos axiomas e leis científicas, os princípios sintetizam uma grande quantidade de informação de um setor ou de todo o ordenamento jurídico, conferindo-lhe unidade e ordenação. (BARCELLOS, 2002, p. 48-49).

Como se percebe, afastando-se da forma de aplicação, os demais critérios, que foram chamados de "secundários", mostram-se pouco confiáveis. Critérios como o do compromisso histórico ou da fundamentalidade parecem verdadeiros apenas em alguns ordenamentos jurídicos específicos ou para alguns ramos do Direito (como o Constitucional). Este parece ser o motivo que levou Humberto Ávila a concentrar as suas críticas à distinção tradicional entre princípios e regras justamente no critério da forma de aplicação.

Humberto Ávila (2013, p. 48-55) defende que o critério tradicional construído por Dworkin e Alexy, que chama de "modo final de aplicação", deve ser parcialmente reformado. Primeiramente o autor critica a concepção da forma de aplicação das regras pela fórmula do "tudo ou nada", uma vez que essa posição partiria de um pressuposto equivocado: de que o texto objeto da interpretação é o responsável por determinar a sua própria forma de aplicação. Para Ávila isso não é verdade, uma vez que o modo de aplicação é "decorrente de conexões axiológicas que são construídas (ou, no mínimo, coerentemente intensificadas) pelo intérprete, que pode inverter o modo de aplicação havido inicialmente como elementar" (ÁVILA, 2013, p. 49). 
Assim sendo, na concepção do autor, não é verdade que a consequência de uma regra sempre deverá ser implementada, no caso concreto, caso ela seja válida, já que a atividade interpretativa do aplicador poderia indicar razões para que a consequência não seja implementada ou, ainda, apenas parcialmente implementada. Implementação gradual da consequência é tipicamente atribuída aos princípios, sendo, portanto, impossível distinguir as espécies normativas baseando-se nesse critério. Nas palavras do autor:

[...] a consequência estabelecida prima facie pela norma pode deixar de ser aplicada em face de razões substanciais consideradas pelo aplicador, mediante condizente fundamentação, como superiores àquelas que justificam a própria regra. Ou se examina a razão que fundamenta a própria regra (rule's purpose) para compreender, restringindo ou ampliando, o conteúdo de sentido da hipótese normativa, ou se recorre a outras razões, baseadas em outras normas, para justificar o descumprimento daquela regra (over ruling). Essas considerações bastam para demonstrar que não é adequado afirmar que as regras "possuem" um modo absoluto "tudo ou nada" de aplicação. Também as normas que aparentam indicar um modo incondicional de aplicação podem ser objeto de superação por razões não imaginadas pelo legislador para os casos normais. (ÁVILA, 2013, p. 51).

Para Humberto Ávila (2013, p. 52), ainda, é comum que existam nas regras expressões "cujo âmbito de aplicação não é (total e previamente) delimitado", dando grande margem de apreciação ao intérprete. Nesses casos, mais uma vez, o caráter absoluto da implementação da consequência da regra válida ficaria prejudicado, já que a própria incidência da norma dependeria de uma ação interpretativa, que é diferente de seu próprio texto.

Se a ação interpretativa garante ao aplicador maleabilidade suficiente para negar, inclusive parcialmente, a consequência (que deveria ser absoluta) de uma regra, então não existe qualquer diferença entre regras e princípios sob esse critério, uma vez que são aplicados de forma idêntica. Desta forma, os princípios teriam um grau de abstração maior do que o das regras apenas quando considerados anteriormente à atividade interpretativa:

A única diferença constatável continua sendo o grau de abstração anterior à interpretação (cuja verificação também depende de prévia interpretação): no caso dos princípios o grau de abstração é maior relativamente à norma de comportamento a ser determinada, já que eles não se vinculam abstratamente a uma situação específica [...]; no caso das regras as consequências são de pronto verificáveis, ainda que devam ser corroboradas por meio do ato de aplicação. Esse critério distintivo entre princípios e regras perde, porém, parte de sua importância quando se constata, de um lado, que a aplicação das 
regras também depende da conjunta interpretação dos princípios que a elas digam respeito $[\ldots]$ e, de outro, que princípios normalmente requerem a complementação de regras para serem aplicados. (ÁVILA, 2013, p. 52-53).

Humberto Ávila também contesta a noção popularizada por Robert Alexy de que princípios, ao contrário das regras, são aplicados de forma gradual, ou "na maior medida do possível". Para o autor, na verdade, "é o estado das coisas que pode ser mais ou menos aproximado, dependendo da conduta adotada como meio" (ÁVILA, 2013, p. 55). Há uma aparente inversão de causa e efeito. O intérprete não averigua os fatos e decide aplicar o princípio gradualmente de acordo com sua incidência sobre esses fatos, mas, é o próprio estado das coisas, é o próprio mundo dos fatos, que se mostra mais ou menos "coincidente" com o abstratamente previsto pelo princípio. Se não há gradação da norma-princípio, mas, na verdade, são os fatos mais ou menos identificados com o proposto, os princípios acabam sendo aplicados ou não no caso concreto.

Para a corrente tradicional, como foi visto, aplicação "tudo ou nada" é um fenômeno típico das regras e não dos princípios. Nesse sentido:

[...] o princípio é ou não aplicado: ou o comportamento necessário à realização ou preservação do estado de coisas é adotado, ou não é adotado. Por isso, defender que os princípios sejam adotados de forma gradual é baralhar a norma com aspectos exteriores, necessários à sua aplicação.

O ponto decisivo não é, portanto, o suposto caráter absoluto das obrigações estatuídas pelas regras, mas o modo como as razões que impõem a implementação das suas consequências podem ser validamente ultrapassadas; nem a falta de consideração a aspectos concretos e individuais pelas regras, mas o modo como essa consideração deverá ser validamente fundamentada - o que é algo diverso. (ÁVILA, 2013, p. 55)

Com fulcro nas extensas críticas formuladas à concepção tradicional, Humberto Ávila acaba construindo sua própria proposta de distinção entre princípios e regras. Essa distinção leva em consideração três critérios: "natureza do comportamento prescrito", "natureza da justificação exigida" e "medida de contribuição para a decisão".

Para o primeiro critério (ÁVILA, 2013, p. 78), regras e princípios se diferem "quanto ao modo como prescrevem o comportamento". As regras são normas "imediatamente descritivas", uma vez que prescrevem obrigações, permissões e proibições por meio da descrição de uma conduta a ser seguida. Os princípios, por outro lado, descrevem um "estado ideal de coisas a ser atingido" (ÁVILA, 2013, p.78), ou seja, são normas finalísticas. “Daí afirmar-se que os princípios são 
normas-do-que-deve-ser (ought-to-be-norms): seu conteúdo diz respeito a um estado ideal de coisas (state of affairs). [...] as regras são normas-do-que-fazer (ought-to-donorms): seu conteúdo diz diretamente respeito a ações (actions)." (ÁVILA, 2013, p. 78-79).

Para o critério da natureza da justificação exigida, as regras não se distinguem dos princípios pela forma de sua aplicação (tudo ou nada para as regras ou maior medida possível para os princípios), mas pelo modo de justificação necessário à aplicação:

\begin{abstract}
A interpretação e aplicação das regras exigem uma avaliação da correspondência entre a construção conceitual dos fatos e construção conceitual da norma e da finalidade que lhe dá suporte, ao passo que a interpretação e a aplicação dos princípios demandam uma avaliação da correlação entre o estado de coisas posto como fim e os efeitos decorrentes da conduta havida como necessária (ÁVILA, 2013, p. 80).
\end{abstract}

O último critério, da medida de contribuição para a decisão, define que os princípios "são normas primariamente complementares e preliminarmente parciais" (ÁVILA, 2013, p. 83), já que tratam de apenas aspectos parciais do caso concreto, não possuindo a pretensão de gerar uma solução específica, mas de contribuir, junto com diversas outras razões, para a tomada de decisão. As regras, por outro lado, "consistem em normas preliminarmente decisivas e abarcantes" (ÁVILA, 2013, p.83), uma vez que aspiram a gerar, em um conflito de razões, uma solução específica. "O preenchimento das condições de aplicabilidade é a própria razão de aplicação das regras". (ÁVILA, 2013, p. 84).

Finalmente, conclui o autor com suas próprias definições para regras e princípios:

As regras são normas imediatamente descritivas, primariamente retrospectivas e com pretensão de decidibilidade e abrangência, para cuja aplicação se exige a avaliação da correspondência, sempre centrada na finalidade que lhes dá suporte ou nos princípios que lhes são axiologicamente sobrejacentes, entre a construção conceitual da descrição normativa e a construção conceitual dos fatos.

Os princípios são normas imediatamente finalísticas, primariamente prospectivas e com pretensão de complementariedade e de parcialidade, para cuja aplicação se demanda uma avaliação da correlação entre estado de coisas a ser promovido e os efeitos decorrentes da conduta havida como necessária à sua promoção. (ÁVILA, 2013, p. 85).

É importante lembrar que o autor não adotou a tradicional partição das normas em regras e princípios, defendendo a necessidade de elaboração de uma 
terceira espécie do gênero norma: os postulados normativos. Em síntese, eles seriam normas situadas em um segundo grau (no "terreno das metanormas") que "[...] instituem os critério de aplicação de outras normas situadas no plano do objeto da aplicação." (ÁVILA, 2013, p. 143).

A obra de Humberto Ávila foi muito bem recebida pelos estudiosos, tendo rapidamente se tornado parte do roteiro obrigatório dos estudos a respeito de normas, regras e princípios. Sendo assim, sua teoria será de grande valia para demonstrar como a função social da propriedade rural é, na realidade, uma regra.

\section{A REGRA CONSTITUCIONAL DA FUNÇÃO SOCIAL DA PROPRIEDADE RURAL}

Como leciona Humberto Ávila (2013, p. 33-34), a norma é um sentido construído a partir da interpretação sistemática de um ou mais dispositivos do texto legal. Não existe, assim, uma relação de equivalência numérica entre dispositivos e normas. Existem normas sem correspondência direta de dispositivos (por exemplo, alguns princípios tácitos) assim como existem normas unitárias construídas a partir de diversos dispositivos. Este é o caso da função social da propriedade rural. Trata-se de uma única norma, construída a partir da interpretação de dois dispositivos constitucionais: o art. $5^{\circ}$, XXII, e o art. 186:

Art. $5^{\circ}$ - Todos são iguais perante a lei, sem distinção de qualquer natureza, garantindose aos brasileiros e aos estrangeiros residentes no País a inviolabilidade do direito à vida, à liberdade, à igualdade, à segurança e à propriedade, nos termos seguintes:

XXIII - a propriedade atenderá a sua função social;

$[\ldots]$

Art. 186 - A função social é cumprida quando a propriedade rural atende, simultaneamente, segundo critérios e graus de exigência estabelecidos em lei, aos seguintes requisitos:

I - aproveitamento racional e adequado;

II - utilização adequada dos recursos naturais disponíveis e preservação do meio ambiente;

III - observância das disposições que regulam as relações de trabalho;

IV - exploração que favoreça o bem-estar dos proprietários e dos trabalhadores. (BRASIL, 1988).

Baseando-se nestes dispositivos, os estudiosos do direito agrário brasileiro passaram a defender a existência da função social da propriedade rural na forma de princípio. Apesar de serem diversos os exemplos desse posicionamento, toma-se a obra de Benedito Ferreira Marques: 
É bastante atual a afirmação de que a função social do imóvel rural é o centro em torno do qual gravita toda a doutrina do Direito Agrário. Essa afirmação não é de todo desarrazoada. $[\ldots]$

No Brasil, particularmente, esse princípio está profundamente arraigado, de sorte que a legislação agrária dele se ocupa em diferentes textos, como a dizer que ele constitui, realmente, o cerne do jus agrarismo. (MARQUES, 2011, p. 33-34).

Chega-se a afirmar que os incisos do art. 186, da Constituição, dão origem, cada um, a novos princípios: “Destacam-se três princípios a serem cumpridos pelo proprietário rural no que tange à função social do imóvel rural: o ecológico, o social e o econômico." (PASSOS, 2004, p. 44). Percebe-se, assim, que não há efetiva preocupação com a classificação da função social da propriedade rural dentre as espécies normativas. $\mathrm{O}$ foco dos estudos é no conteúdo jurídico e filosófico do termo.

É possível identificar dois fatores responsáveis pela confusão conceitual. Em primeiro lugar, há preponderância do disposto no art. $5^{\circ}$, XXII, sobre o art. 186, ambos da Constituição. Apesar de não existir hierarquia entre dispositivos constitucionais, nota-se que os estudiosos relegam ao art. 186 papel coadjuvante ao promover a interpretação que dá origem à regra da função social da propriedade rural.

Uma boa explicação para o fenômeno se encontra na localização dos artigos dentro da Constituição, além de sua estrutura gramatical e conteúdo. A Constituição de 1988, como se sabe, foi recebida com verdadeiro entusiasmo pelos juristas brasileiros. É comum referirem-se a ela como uma "Carta Cidadã", que "emergiu o povo brasileiro da noite autoritária" (MARÉS, 2003, p. 114). Uma de suas mais exaltadas novidades, sem dúvida, foi o extenso rol de direitos e garantias individuais, cujo protagonista é exatamente o artigo quinto e seus incisos. Dessa forma, ainda que sistematicamente não exista hierarquia entre dispositivos constitucionais, é inegável que os juristas muitas vezes dão preponderância (ou pelo menos maior atenção) à nova carga principiológica com sua recémconquistada "força normativa", relegando injustificadamente papel secundário à outras normas, especialmente regras. A função social da propriedade rural, então, adquire contorno de princípio por dissociação do art. 186 da Carta Maior.

Ademais, a estrutura gramatical e o conteúdo do disposto no inciso XXII, do art. $5^{\circ}$, da Constituição, possuem inegável conotação política e filosófica, para além de jurídica. "A propriedade atenderá a sua função social". Trata-se de um ataque à noção de propriedade absoluta, tão criticada anteriormente. $O$ inciso não elenca as formas pelas quais a propriedade deve atender a função social. Não 
existem condicionantes para seu cumprimento. A estrutura do dispositivo é típica daqueles que dão origem a princípios, por meio de sua interpretação. Deve-se lembrar, também, que o âmbito de aplicação desse inciso é muito maior do que o do art. 186, que trata apenas da propriedade rural.

O segundo fator que podemos identificar é, como já citado, a resistência de alguns estudiosos em admitir a inexistência de relação unitária entre dispositivos e normas. A interpretação conjunta de dois dispositivos da Constituição, o inciso XXII, do art. $5^{\circ}$, e o art. 186, dão origem a uma única regra: a função social da propriedade rural. Em geral, a doutrina a trata como princípio derivado exclusivamente do inciso XXII, do art. $5^{\circ}$, da Constituição, rebaixando o art. 186 a uma regra existente apenas para lhe dar contornos mais sólidos. Não é o caso. Só existe função social da propriedade rural após a interpretação conjunta dos dois dispositivos, o que garante a existência de uma única norma: a regra da função social da propriedade rural.

Quando efetivamente percebemos que não existe hierarquia entre os dois dispositivos constitucionais e que ambos são igualmente necessários durante o processo interpretativo para a construção da função social da propriedade rural, é fácil perceber como a norma tem natureza de regra.

Tomemos a teoria tradicional da diferenciação entre princípios e regras, na qual o critério preponderante é o do modo de aplicação: regras são aplicadas na forma do "tudo ou nada" e princípios "na maior medida do possível". Se fosse levado em consideração apenas o inciso XXII, do art. $5^{\circ}$, da Constituição, teríamos claramente um princípio jurídico, uma vez que o enunciado "a propriedade atenderá a sua função social" claramente institui uma obrigação jurídica a ser observada na maior medida do possível. Todavia, o mesmo deixa de ser verdade ao observar o art. 186, que institui quatro requisitos que devem ser obedecidos simultaneamente para que se possa afirmar que uma propriedade cumpre sua função social. Ao considerar os dois dispositivos conjuntamente, percebe-se que a função social para a propriedade rural tem natureza de regra.

Uma propriedade atende ou não a sua função social. Para que ela atenda, deve, simultaneamente, obedecer a quatro requisitos: "aproveitamento racional e adequado", "utilização adequada dos recursos naturais disponíveis e preservação do meio ambiente", "observância das disposições que regulam as relações de trabalho" e "exploração que favoreça o bem-estar dos proprietários e dos trabalhadores". Se um único desses requisitos não for respeitado, tem-se que a propriedade não obedece a sua função social. Trata-se de uma hipótese clara de aplicação "tudo ou nada", tipicamente atribuída às regras. Se uma propriedade atende aos quatro 
requisitos do art. 186 da Constituição, terá a proteção do ordenamento jurídico. Se, por outro lado, não obedecer a qualquer desses requisitos, sofrerá as consequências também previstas por lei, dentre as quais a mais conhecida é a constante no art. 184 da Carta Magna: a propriedade se tornará passível de desapropriação para fins de reforma agrária.

O aproveitamento da propriedade é racional ou não. Não se está pedindo uma máxima observância no caso concreto, mas sim que critérios definidos em lei infraconstitucional sejam respeitados. Da mesma forma para os demais incisos do artigo: a utilização dos recursos naturais será adequada ou não, a legislação trabalhista será observada ou não e a exploração da propriedade irá favorecer ou não o bem-estar de proprietários e trabalhadores. A regra não admite gradações. Observam-se os critérios estabelecidos por lei por sua própria imperatividade ou a propriedade não obedecerá sua função social. Se um único desses requisitos for desobedecido, têm-se que toda propriedade não obedece a função social.

Mesmo levando em consideração as críticas formuladas por Humberto Ávila a respeito da repartição tradicional das normas em regras e princípios, temos que a função social da propriedade rural mantém sua natureza de regra. Para o autor:

As regras são normas imediatamente descritivas, primariamente retrospectivas e com pretensão de decidibilidade e abrangência, para cuja aplicação se exige a avaliação da correspondência, sempre centrada na finalidade que lhes dá suporte ou nos princípios que lhes são axiologicamente sobrejacentes, entre a construção conceitual da descrição normativa e a construção conceitual dos fatos. (ÁVILA, 2013, p. 85).

Como visto, as regras, para Ávila (2013, p. 85), são identificadas por meio de quatro requisitos: o dever imediato de promover uma conduta descrita, o dever mediato de se manter fiel aos princípios superiores e finalidades subjacentes, manter a justificação, que é a correspondência entre o conceito da norma e o conceito do fato e, finalmente, uma pretensão concreta de decidibilidade, especialmente quando isoladamente considerada.

Esses requisitos são facilmente identificáveis na regra da função social da propriedade rural. Em primeiro lugar, as condutas necessárias (art. 186 da Constituição) para cumprir o fim desejado (art. $5^{\circ}$, inc. XXII, da Constituição) são meticulosamente descritas pelos dispositivos da norma. O fim almejado é a obediência da função social, que é atingido por meio do respeito ao aproveitamento racional da propriedade, da adequada utilização dos recursos naturais, da observância à legislação trabalhista e do favorecimento ao bem estar de proprietários e trabalhadores. 
Se princípio fosse, promoveria um estado ideal de coisas por meio da adoção das condutas necessárias. "A instituição do fim é o ponto de partida para a instituição dos meios." (ÁVILA, 2013, p. 86), ou seja, seria juridicamente possível, ao julgador, no caso concreto, entender que existiriam outras condutas obrigatórias para atingir a finalidade almejada pela norma. No Brasil, por exemplo, existe uma demanda muito antiga para que o tamanho da propriedade rural seja um dos requisitos para cumprimento de sua função social. O Estatuto da Terra (Lei 4.504/64), de certa forma, incorpora tais ideias: tanto o minifúndio quanto o latifúndio são entendidos como males (art. $11, \S 2^{\circ}$ ). Poderia então o juiz decidir que um latifúndio, devido à sua enorme extensão, não atende à função social e, portanto, seria passível de desapropriação para a reforma agrária? A resposta é não, uma vez que a função social da propriedade rural é uma regra, que, por sua própria natureza, descreve as condutas necessárias a sua própria obediência (muito embora a convicção pessoal do jurista muitas vezes grite em sentido contrário).

A função social da propriedade rural, como regra, também obedece ao seu dever imediato de ser fiel aos princípios superiores e finalidades subjacentes. Há perfeita consonância entre os requisitos estabelecidos pelos dispositivos constitucionais e a visão geral da Constituição sobre a propriedade e sobre os direitos e garantias do indivíduo e da sociedade como um todo. Percebe-se claramente a intenção de proteger outros valores constitucionais, como a salubridade das relações de trabalho, a proteção ao meio ambiente e a própria função econômica da propriedade.

A correspondência entre o "conceito da norma e o conceito do fato" (ÁVILA, 2013, p. 85) também é facilmente averiguável. Ao contrário do que geralmente se observa em princípios clássicos, como o da razoabilidade, a função social da propriedade rural exige uma justificação menor do interprete que busca a sua concretização. As condutas exigidas estão descritas na lei, assim como a sua consequência. Se se tratasse de princípio, que em geral não descreve abstratamente as condutas necessárias para a persecução de seu fim, a obrigação de justificação do aplicador seria muito maior. As descrições contidas no art. 186 determinam de forma direta os caminhos a serem percorridos para a concretização de sua consequência. A propriedade que promover um aproveitamento racional e adequado, que utilizar adequadamente os recursos naturais, obedecer a legislação trabalhista e favorecer, em sua exploração, o bem-estar de proprietários e trabalhadores terá a proteção do ordenamento jurídico.

Por último, segundo Humberto Ávila (2013, p. 85), as regras também possuem, em relação à pretensão de decidibilidade, "exclusividade e abarcância". 
Significa dizer que a regra, por meio da interpretação dos dispositivos que lhe dão origem, tem a intenção de " $[$...] abranger todos os aspectos relevantes para a tomada da decisão, têm a pretensão de gerar uma solução específica para a questão" (ÁVILA, 2013, p. 84). Talvez seja este o requisito em que se vê a natureza de regra de forma mais patente: a interpretação do inciso XXII, do art. $5^{\circ}$, e do art. 186, da Constituição é capaz de determinar se uma propriedade rural cumpre ou não sua função social. As normas infraconstitucionais servirão apenas para auxiliar o intérprete na averiguação de cumprimento dos requisitos. Tratase de um auxílio prático, todavia, os critérios de decidibilidade estão contidos exclusivamente na regra. A legislação ordinária serve apenas para regulamentar aquilo que a Constituição criou.

Pelo exposto, percebe-se que a função social da propriedade rural, extraída da interpretação do art. $5^{\circ}$, XXII, e art. 186 da Constituição, possui a natureza jurídica de regra, ao contrário do que os estudiosos geralmente afirmam.

\section{CONCLUSÃO}

Existem dois critérios geralmente aceitos pelos juristas para averiguar a diferença entre as espécies do gênero norma. O critério tradicional, elaborado por Ronald Dworkin e Robert Alexy, foca-se no modo de aplicação da norma para estabelecer a diferença: as regras são aplicadas na forma de "tudo ou nada" enquanto os princípios são aplicados "na maior medida do possível”. O modo de aplicação das regras relaciona-se com sua própria validade. Ocorrendo a hipótese de aplicação da regra, sua consequência deverá ser implementada, sendo a regra válida. Os princípios, por outro lado, são vistos, na expressão de Alexy, como "mandamentos de otimização". Sua implementação pode ocorrer de forma gradual, fugindo do "tudo ou nada".

Apesar de serem posições muito respeitadas e as verdadeiras responsáveis pela popularização dos debates a respeito de princípios e regras, o critério tradicional sofreu algumas críticas. Dentre os juristas brasileiros, Humberto Ávila é geralmente apontado como um dos principais defensores da reformulação dos critérios. Para o autor, primeiramente, não é correto afirmar que as regras são aplicadas na forma do "tudo ou nada", uma vez que essa concepção pressupõe que a forma gramatical do dispositivo seria responsável por determinar sua forma de aplicação. Para Ávila o processo de aplicação é, antes de tudo, uma interpretação, que não é determinantemente influenciada pela disposição gramatical do texto da norma. 
Ávila também critica a concepção de aplicação de princípios "na maior medida do possível". Para o autor, o que é gradual, na realidade, é a aproximação do estado das coisas em relação ao princípio extraído do texto legal. Assim, o mundo dos fatos que é mais ou menos coincidente com o abstratamente previsto no princípio. Com fulcro nas críticas expostas, o autor elabora, assim, seu próprio conceito de regras e princípios.

A norma é uma relação de sentido construída direta ou indiretamente a partir da interpretação de um ou mais dispositivos. No caso da regra da função social da propriedade rural, esse sentido é construído a partir da interpretação de dois dispositivos: o inciso XXII, do art. $5^{\circ}$, e o art. 186, ambos da Constituição Federal. A dissociação entre os dois dispositivos é responsável pela errônea concepção, comumente aceita pelos estudiosos nacionais, de que a função social da propriedade rural possui natureza normativa de princípio e não de regra.

A constatação da natureza de regra da função social da propriedade rural, utilizando-se dos critérios tradicionais de diferenciação das espécies normativas, se dá por meio do modo de aplicação da norma. Apesar de o inciso XXII, do art. $5^{\circ}$, da Constituição ter estrutura compatível com a classicamente atribuída aos dispositivos que dão origem a princípios, a sua interpretação conjunta com o art. 186 da Carta Maior muda completamente o panorama. Esse artigo dispõe, em seus incisos, quatro requisitos de obediência necessária e concomitante para que a propriedade rural exerça sua função social. A norma apresenta, dessa maneira, aplicação "tudo ou nada", uma vez que se qualquer desses requisitos não for respeitado, tem-se que toda a propriedade não obedece a função social. Sendo assim, para a construção tradicional, trata-se de uma regra.

Ainda que o critério adotado para a diferenciação das espécies normativas seja o elaborado por Humberto Ávila, também se chega à conclusão de que se trata de uma regra e não de um princípio. Para o autor, as regras possuem um dever imediato de buscar a adoção de condutas descritas, dever mediato de se manter fiéis à suas finalidades subjacentes e a princípios superiores, uma obrigação de correspondência entre o conceito da norma e o conceito do fato e a pretensão exclusiva de decidibilidade.

Todos esses requisitos são verificáveis na regra da função social da propriedade rural. Apesar de o inciso XXII, do art. $5^{\circ}$, da Constituição tratar a função social como um fim a ser atingido, o art. 186 elenca um rol de condutas meticulosamente descritas para que se averigue de fato se a propriedade cumpriu sua função social. Tanto a finalidade quanto as condutas descritas traduzem diversos outros valores protegidos pela Carta Magna, tais como a proteção da 
salubridade das relações de trabalho, a proteção do meio ambiente e a função econômica da propriedade rural. Da mesma forma, percebe-se que se trata de uma relação entre os conceitos descritos na regra e o mundo dos fatos. Existindo respeito fático a todas as condições definidas anteriormente pela regra, haverá proteção à propriedade que cumpriu sua função social. Finalmente, a regra também possui pretensão exclusiva de decidibilidade. Utilizando-se apenas da norma é possível averiguar se uma propriedade atende ou não a sua função social. A legislação infraconstitucional existe apenas para regulamentar o que a regra constitucional criou.

Desta forma, independentemente dos critérios de diferenciação adotados pelo jurista, seja o clássico ou o formulado por Humberto Ávila, a norma da função social da propriedade rural possui natureza jurídica de regra.

\section{REFERÊNCIAS}

ALEXY, Robert. Teoria dos direitos fundamentais. Trad. Virgílio Afonso da Silva. São Paulo: Malheiros, 2008.

ÁVILA, Humberto. Teoria dos princípios: da definição à aplicação dos princípios jurídicos. 14. ed. at. São Paulo: Malheiros, 2013.

BARCELLOS, Ana Paula de. A eficácia jurídica dos princípios constitucionais: o princípio da dignidade da pessoa humana. Rio de Janeiro: Renovar, 2002.

BARROSO, Luís Roberto; BARCELlOS, Ana Paula de. O começo da história: a nova interpretação constitucional e o papel dos princípios no Direito brasileiro. In: SILVA, Virgílio Afonso da (Org.). Interpretação constitucional. São Paulo: Malheiros, 2005.

BOBBIO, Norberto. Teoria da norma jurídica. Trad. Fernando Pavan Baptista e Ariani Bueno Sudatti. Bauru: Edipro, 2001.

BORGES, Paulo Torminn. Institutos básicos do Direito Agrário. 11. ed. São Paulo: Saraiva, 1998.

BRASIL. Constituição (1988). Constituição da República Federativa do Brasil. Brasília: Senado, 1988.

BRASIL. Decreto-lei 4.657, de 09 de setembro de 1942. Lei de Introdução às Normas do Direito Brasileiro. Diário Oficial, Rio de Janeiro, p. 1, 9 set. 1942.

BRASIL. Lei 4.504, de 30 de novembro de 1964. Dispõe sobre o Estatuto da Terra e dá outras providências. Diário Oficial, Brasília, p. 49, 30 nov. 1964.

CANOTILHO, José Joaquim Gomes. Direito Constitucional. 5. ed. Coimbra: Almedina, 1991.

CARROZZA, Antonio; ZELEDÓN, Ricardo Z. Teoría general e institutos de Derecho Agrario. Buenos Aires: Astrea, 1990.

DWORKIN, Ronald. Levando os direitos a sério. Trad. Nelson Boeira. São Paulo: WMF Martins Fontes, 2010.

HART, H.L.A. O conceito de Direito. Trad. Antônio de Oliveira Sette-Câmara. São Paulo: WMF Martins Fontes, 2009. 
LARANJeIRA, Raymundo. Propedêutica do Direito Agrário. São Paulo: LTr, 1975.

MARÉS, Carlos Frederico. A função social da terra. Porto Alegre: Sergio Antonio Fabris, 2003.

MARQUES, Benedito Ferreira. Direito Agrário Brasileiro. 9. ed. ver. amp. São Paulo: Atlas, 2011.

PASSOS, Cristiane Lisita. A Função social do imóvel rural. In: BARROSO, Lucas Abreu; PASSOS, Cristiane Lisita (Orgs.). Direito Agrário contemporâneo. Belo Horizonte: Del Rey, 2004.

SILVA, José Afonso da. Curso de Direito Constitucional positivo. 10. ed. São Paulo: Malheiros, 1994.

SILVA, Luís Virgílio Afonso da. O proporcional e o razoável. Revista dos Tribunais. São Paulo, ano 91, v. 798, p. 23-50, abr. 2002.

Princípios e regras: mitos e equívocos acerca de uma distinção. Revista Latino-americana de Estudos Constitucionais. Belo Horizonte, v. 1, p. 609-627, 2003.

TANAJURA, Grace Virgínia Ribeiro de Magalhães. Função social da propriedade rural: com destaque para a terra no Brasil contemporâneo. São Paulo: LTr, 2000.

TRENTINI, Flavia. Teoria geral do Direito Agrário contemporâneo. São Paulo: Atlas, 2012.

Recebido: maio 2013

Aprovado: novembro 2013 